\title{
TEKNIK PENYUSUNAN ARAH DAN KEBIJAKAN UMUM APBD
}

\author{
H. Aban Subandi \\ Universitas Islam Syeh-Yusuf Tangerang \\ subandiaban97@gmail.com
}

\begin{abstract}
Abstrak
Dalam pelaksanaan otonomi daerah secara luas, nyata, dan bertanggungjawab, diperlukan adanya reformasi anggaran. Aspek utama dari reformasi anggaran adalah perubahan anggaran dari tradisional budget kepada performance budget, dan salah satu komponen yang harus dikembangkan dalam rangka melaksanakan performance budget adalah menyusun Arah dan Kebijakan Umum APBD. Arah dan Kebijkaan umum merupakan pedoman bagi Pemerintah Daerah dalam melaksanakan berbagai kegiatan pelayanan publik agar dapat mencapai tujuan dan sasaran secara efektif. Arah dan Kebijakan Umum APBD memuat komponenkomponen pelayanan dan tingkat pencapaian yang diharapkan pada setiap bidang kewenangan Pemerintah Daerah yang akan dilaksanakan dalam satu tahun anggaran. Penyusunan Arah dan Kebijakan Umum APBD, harus memperhatikan Rencana Strategis Daerah, Hasil evaluasi kinerja pemerintah periode sebelumnya, pokok pikiran APBD dan arahan dari pemerintah pusat. Arah dan Kebijakan Umum APBD yang disusun harus memuat petunjuk dan ketentuan-ketentuan umum yang disepakati sebagai pedoman dalam penyusunan APBD. Dalam sistem anggaran kinerja, Arah dan Kebijakan Umum APBD disamping merupakan instrument perencanaan anggaran juga sebagai dasar untuk penilaian kinerja keuangan daerah.

Kata Kunci: Otonomi daerah, performance budgeting, pohon masalah, pohon sasaran, pohon alternatif, strategi SWOT, dan arah kebijakan.
\end{abstract}

\footnotetext{
Abstract

In implementing regional autonomy in a broad, tangible, and responsible manner, budget reform is needed. The main aspect of budget reform is the budget of the traditional budget for the performance budget, and one component that must be developed within the framework of budget implementation is to compile the General Budget Directions and Policies. General directions and policies are a guideline for regional governments in carrying out various public service activities in order to effectively achieve their goals and objectives. APBD General Direction and Policy. Service components and expected level of approval in each area of authority. Local Government will carry out one fiscal year. Preparation of APBD Direction and General Policy, must consider the Regional Strategic Plan, the results of the evaluation of the performance of the previous period of the government, the main ideas of the Regional Budget and directions from the central government. Directions and APBD General Policies that are compiled must receive instructions and general provisions approved by the $A P B D$. In the performance budget system, APBD Direction and General Policy besides being a budget planning instrument are also the basis for evaluating regional financial performance.
} 
Keywords: Regional autonomy, performance budgeting, problem trees, target trees, alternative trees, SWOT strategies, and policy directions.

\section{Pendahuluan}

Dalam rangka mewujudkan pemerintah yang bersih (clean government), pemenrintahan yang bertanggung jawab (responbility government), dan pemerintahan yang baik (good government), pemerintah berdasarkan UndangUndang Nomor: 32 Tahun 2004 Tentang Pemerintah Daerah, telah memberikan otonomi yang luas, nyata, dan bertanggungjawab kepada Pemerintah Daerah.

Untuk mencapai tujuan tersebut agar berjalan secara efektif, efisien diperlukan kesempurnaan administrasi keuangan daerah, dan oleh karena itu diperlukan reformasi keuangan daerah yang meliputi perubahan struktur anggaran (budget structure reform) yaitu merubah struktur anggaran dari anggaran tradisional yang didominasi oleh penyusunan anggaran yang bersifat line item dan incrementalism menjadi performance budget. Akan tetapi perubahan-perubahan tersebut harus tetap berpegang kepada prinsip-prinsip pengelolaan keuangan daerah yang baik meliputi akuntabilitas, value of money, kejujuran, transparansi, dan pengendalian dan perubahan proses penyusunan APBD (budget process reform) (Mardiasmo, 2002:29).

Salah satu komponen yang harus dikembangkan dalam melaksanakan anggaran kinerja (performance budget), adalah menyusun Arah dan Kebijakan Umum APBD. Yang fungsinya sebagai pedoman bagi pemerintah daerah dalam melaksanakan berbagai kegiatan pelayanan public. Dalam tulisan ini pembahasan arah dan kebijakan umum APBD meliputi (1) pendahuluan, (2) arti, manfaat, dan kegunaan arah dan kebijakan umum, dan (3) teknik penyusunan arah dan kebijakan umum APBD.

\section{Arti Manfaat Arah dan Kebijakan Umum APBD}

Istilah arah dan kebijakan umum APBD terdiri dari tiga kata yaitu arah, kebijakan, dan APBD. Arah mengandung arti tujuan dan sasaran yang ingin dicapai. Sedang kebijakan mengandung arti suatu taktik atau strategi yang diarahkan untuk mencapai suatu tujuan (Raksasataya, dalam Tjokroaminoto, (1976:5). Sementara E. Anderson mengartikan kebijakan adalah serangkaian tindakan yang mempunyai tujuan tertentu yang diikuti dan dilaksanakan oleh seorang pelaku atau sekelompok pelaku guna memecahkan suatu masalah tertentu (Islami, 1997:17). Pengertian APBD adalah rencana keuangan tahunan pemerintahan daerah yang disetujui oleh Dewan Perwakilan Rakyat Daerah (UU Nomor 17 Tahun 2003). Dengan demikian pengertian arah dan kebijakan APBD adalah taktik dan strategi yang berupa tindakan-tindakan atau kegiatan-kegiatan yang dilakukan oleh pemerintah daerah dalam tahun yang akan datang, guna mencapai tujuan dan sasaran yang telah ditetapkan yang dianggarkan pembiayaannya dalam APBD.

Penganggaran daerah terdiri dari formulasi kebijakan anggaran dan perencanaan operasional anggaran. Penyusunan arah dan kebijakan umum APBD termasuk kategori formulasi kebijakan anggaran yang menjadi acuan dalam 
perencanaan operasional anggaran. Formulasi kebijakan anggaran berkaitan dengan analisa fiskal, sedang perencanaan operasional anggaran lebih ditekankan pada lokasi sumber daya.

Arah dan kebijakan umum disingkat AKU, merupakan pedoman bagi pemerintah daerah dalam melaksanakan berbagai kegiatan pelayanan public agar dapat mencapai tujuan dan sasaran secara efektif. Dengan demikian arah dan kebijakan umum APBD tersebut memuat antara lain komponen-komponen pelayanan dan tingkat pencapaian yang diharapkan pada setiap bidang kewenangan pemerintah daerah yang akan dilaksanakan dalam satu tahun anggaran. Dengan terbentuknya arah dan kebijakan umum pemerintah, Dewan Perwakilan Rakyat Daerah (DPRD) dan masyarakat akan mengetahui kearah mana dan bidang apa saja yang menjadi prioritas anggaran pada satu tahun anggaran tertentu.

Menurut Keputusan Menteri Dalam Negeri 29 Tahun 2002, hal penting yang harus diperhatikan dalam penyusunan arah dan kebijakan umum APBD, seperti : rencana strategis daerah, hasil evaluasi kinerja pemerintah periode sebelumnya, pokok pikiran DPRD dan arahan dari pemerintah pusat.

Arah dan kebijakan umum APBD yang disusun harus memuat petunjuk dan ketentuan-ketentuan umum yang disepakati sebagai pedoman dalam penyusunan APBD. Dalam sistem anggaran kinerja, arah dan kebijakan umum APBD disamping merupakan instrument perencanaan anggaran juga sebagai dasar untuk penilaian kinerja keuangan daerah.

Selanjutnya Keputusan Menteri Dalam Negeri Nomor 29 Tahun 2002, mengatakan bahwa arah dan kebijakan umum APBD dapat disusun berdasarkan kriteria sebagai berikut :

1. Sesuai dengan visi, misi, tujuan, sasaran dan kebijakan yang diterapkan dalam rencana strategis daerah dan dokumen perencanaan lainnya yang ditetapkan dalam rencana strategis daerah dan dokumen perencanaan lainnya yang ditetapkan oleh daerah sesuai dengan aspirasi masyarakat yang berkembang dan mempertimbangkan kondisi dan kemampuan daerah saat itu.

2. Memuat arah yang diinginkan dan kebijakan umum yang disepakati sebagai pedoman penyusunan strategi dan prioritas APBD serta rencana APBD dalam satu tahun anggaran yang telah disusun dari hasil kesepakatan bersama antara DPRD dengan Pemerintah Daerah.

3. Memberikan fleksibilitas untuk dijabarkan lebih lanjut dan memberikan peluang untuk pengembangan kreatifitas bagi pelaksanaannya (pihak eksekutif).

Dasar penyusunan arah dan kebijakan umum APBD yang dibuat oleh DPRD dan pemerintah daerah adalah sebagai berikut :

1. Arah dan kebijakan umum APBD pada dasarnya adalah rencana tahunan yang merupakan bagian dari rencana jangka panjang, menengah yang dibuat dalam rencana strategis daerah atau dokumen perencanaan lainnya sebagai dasar penyusunan APBD.

2. Untuk mengantisipasi perubahan lingkungan, pemda dan DPRD perlu melakukan penjaringan aspirasi masyarakat seperti telah disebutkan pada penjelasan di atas. 
3. Penyusunan arah dan kebijakan umum APBD mempertimbangkan laporan histories yang memuat pencapaian kinerja pada tahun-tahun anggaran sebelumnya.

4. Konsep awal arah dan kebijakan umum APBD dapat disusun berdasarkan pokok-pokok pikiran DPRD.

5. Penyusunan arah dan kebijakan umum APBD dapat disusun berdasarkan pokok-pokok kebijakan pengelolaan keuangan daerah dari pemerintah atasan.

6. Pemda dan DPRD dapat melibatkan masyarakat pemerhati atau tenaga ahli untuk penyusunan konsep arah dan kebijakan umum APBD.

7. Hasil kesepakatan mengenai arah dan kebijakan umum APBD selanjutnya dituangkan dalam suatu nota kesepakatan yang ditanda tangani bersama Pemda dan DPRD.

Berdasarkan uraian-uraian tersebut di atas, terlibat dalam gambar 1 dibawah ini.

Gambar 1

Mekanisme penyusunan Arah dan Kebijakan Umum APBD

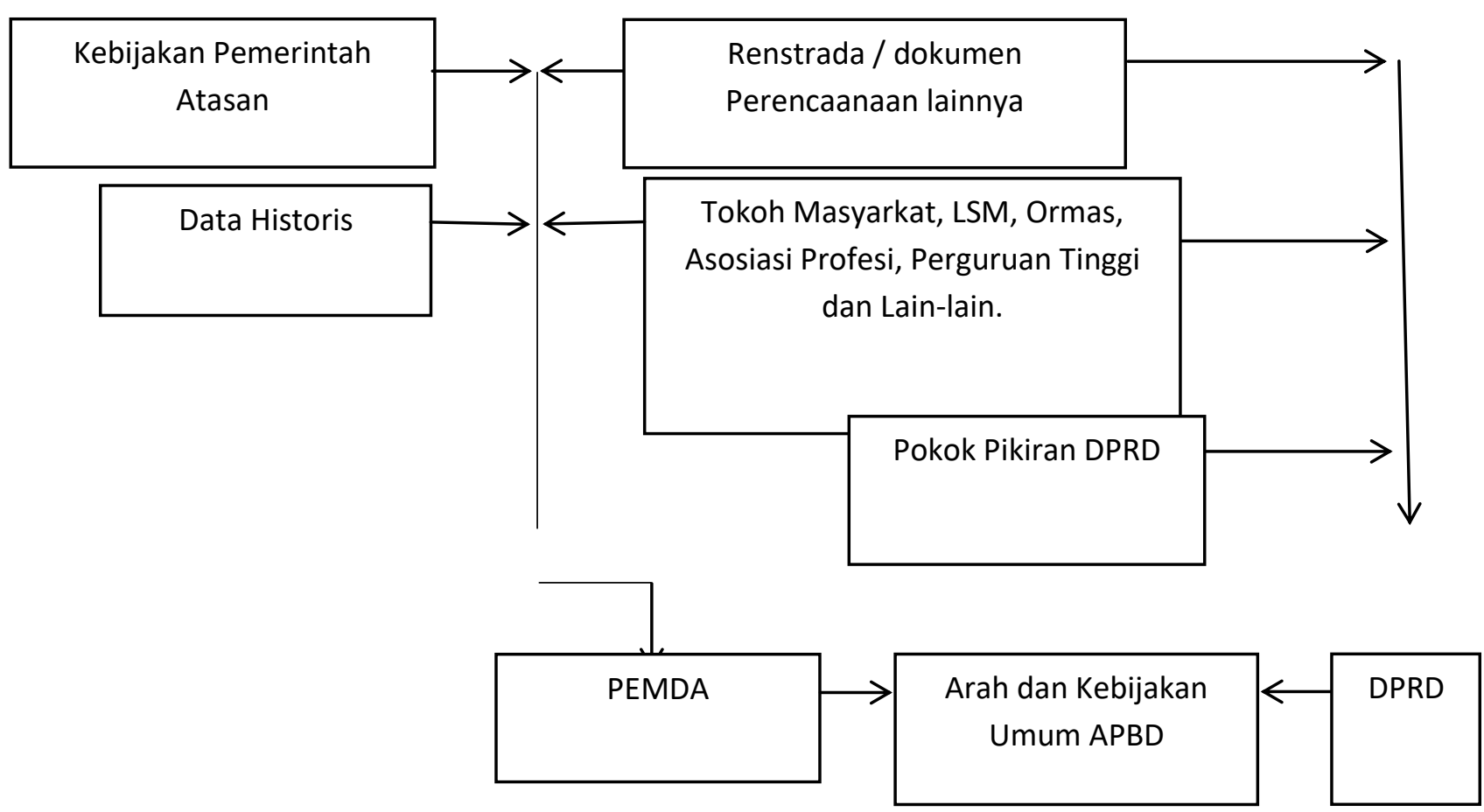

Sumber : Keputusan Menteri Dalam Negeri Nomor 29 Tahun 2003.

\section{Teknik Penyusunan Arah dan Kebijakan Umum}

Sebagaimana telah dikemukakan dimuka bahwa arah mengandung arti tujuan dan sasaran yang ingin dicapai. Sedang kebijakan mengandung arti suatu taktik atau strategi yang diarahkan untuk mencapai suatu tujuan. Dikarenakan adanya masalah tertentu. Dengan demikian penyusunan arah dan kebijakan umum berisi kegiatan-kegiatan yang akan dilakukan pemerintah guna memecahkan 
masalah. Adapun teknik untuk memecahkan masalah, menurut A. Dale Timple (1992:168) menjelaskan : " Proses pemecahan masalah dilakukan secara ilmiah, hal ini meliputi diagnosis, penetapan sasaran, pembuatan beberapa alternatif tindakan, pengevaluasian berbagai alternatif, pemilihan alternatif, pengujian dan pelaksanaan $"$

\section{Contoh Merumuskan Arah dan Kebijakan Umum :}

1. Mengidentifikasi Masalah dan Penyebabnya.

Untuk mengidentifikasi masalah disusun dan dilukiskan sebagai suatu rangkaian sebab akibat, berbentuk sebuah pohon, pohon masalah dimulai dengan masalah yang utama sebagai hasil analisis situasi, dianalisis penyebab masalah tersebut. Pikiran apa akibat yang mungkin akan timbul dari masalah tersebut.

Contoh pohon masalah.

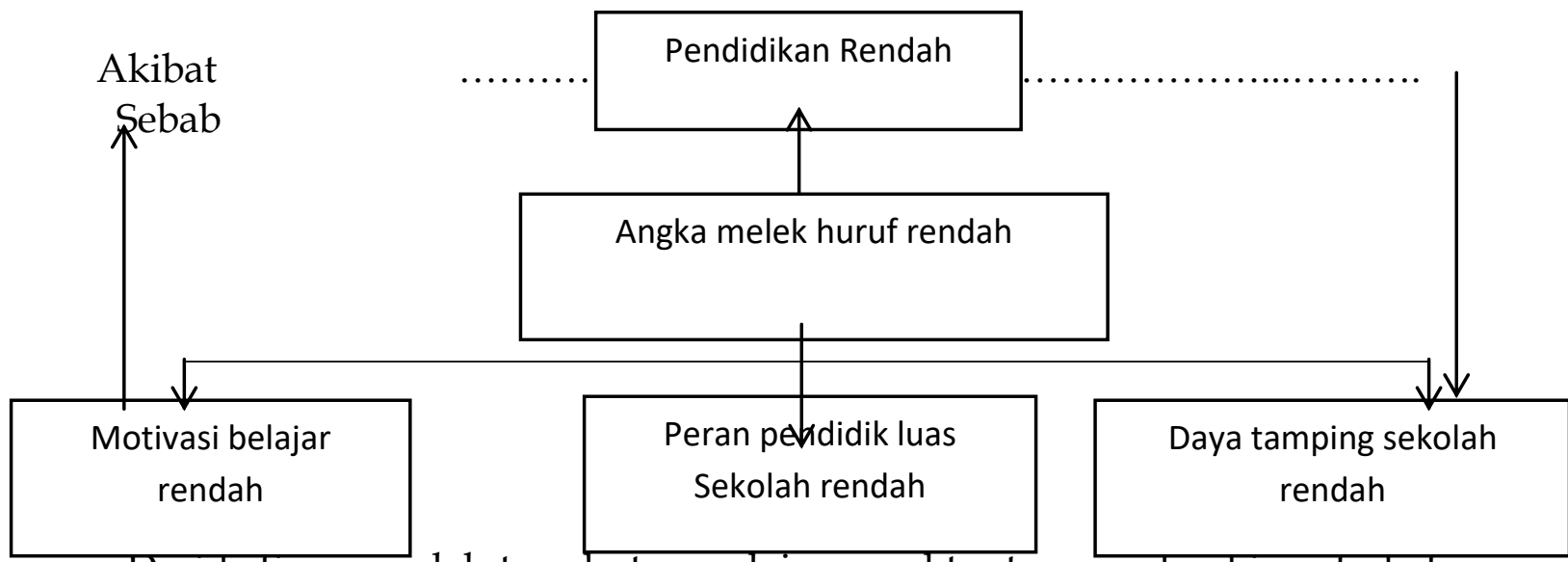

Dar1 ketiga masalah tersebut seandainya waktu, tenaga, dan biaya terbatas, jika ingin memilih masalah yang dominan caranya dengan menggunakan teknik USG (Urgensi, Serious, dan Growth), pemberian nilai menggunakan skala Likeert, seperti contoh dibawah ini.

\begin{tabular}{|c|c|c|c|c|c|c|}
\hline $\begin{array}{l}\mathrm{N} \\
\mathrm{O}\end{array}$ & MASALAH & $\mathrm{U}$ & $S$ & G & TOTAL & PRIORITAS \\
\hline 1 & Motivasi Belajar Rendah & 4 & 4 & 4 & 12 & 2 \\
\hline 2 & $\begin{array}{l}\text { Peran Pendidik Luar Sekolah } \\
\text { Rendah }\end{array}$ & 4 & 3 & 4 & 11 & 3 \\
\hline 3 & Daya Tampung Sekolah Rendah & 5 & 5 & 5 & 15 & 1 \\
\hline
\end{tabular}

Keterangan :

$\mathrm{U}=$ Urgensi (mendesak)

$S=$ Serious (gawat)

$\mathrm{G}=$ Growth (tumbuh,kembang)

Berdasarkan hasil USG tersebut maka masalah dominan yang menjadi prioritas penyelesaian masalah adalah daya tamping sekolah rendah. 


\section{Menetapkan Sasaran}

Untuk menentukan sasaran yang ingin dicapai dengan cara mempositifkan dari pernyataan masalah. Pernyataan sasaran menggunakan kata awalan ter atau awalan me dan akhiran nya (Entang, 2000:29), misalnya : meningkatnya, terkendalinya, hal ini dimaksudkan bahwa sasaran yang akan dicapai, adalah sebagai berikut:

Contoh pohon sasaran

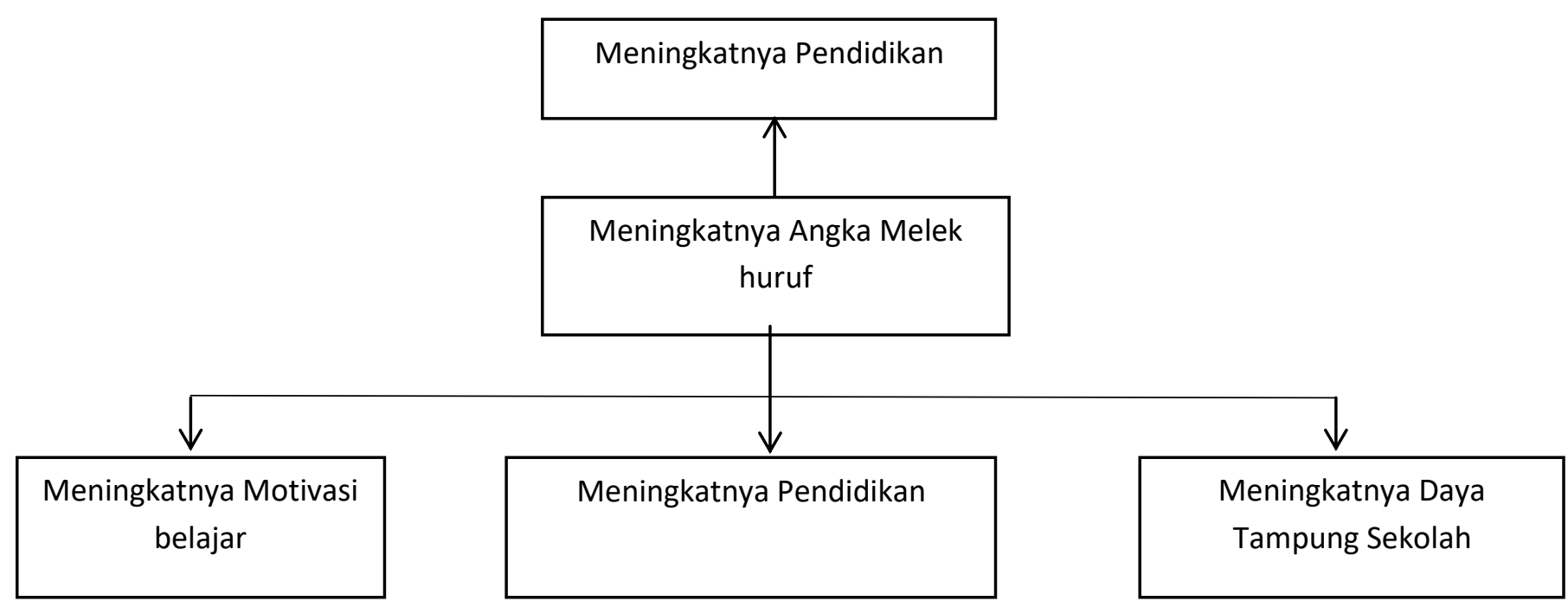

\section{Pohon Alternatif}

Pohon alternatif adalah teknik untuk mengidentifikasi alternative pemecahan masalah atau arah tindakan yang dapat dipakai untuk mewujudkan sasaran tertentu dan melukiskan dalam format sederhana.

Contoh pohon Alternatif.

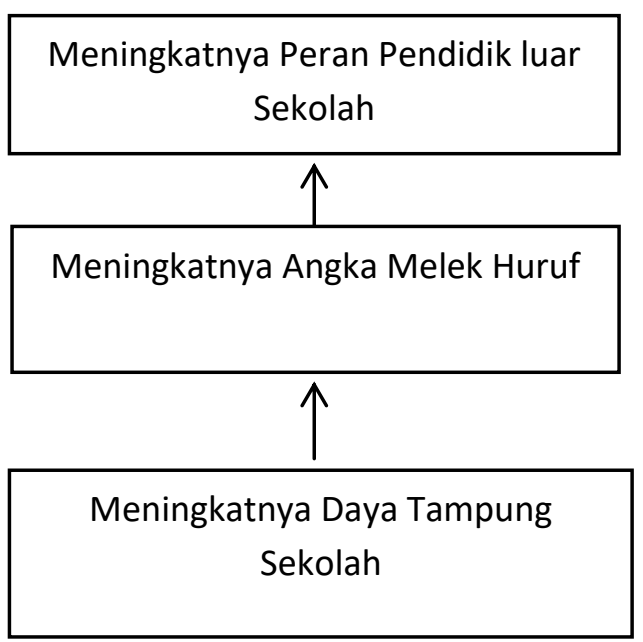




\section{Penetapan Strategi dan Kebijakan}

Untuk membuat kebijakan, teknik yang digunakan adalah mengguakan analisis SWOT adalah singkatan dari Strength, Weakness, Opportunities, dan Threaths (kekuatan). Weakness (kelemahan) mengacu pada factor internal, sedangkan Opportunities (peluang) dan threaths (ancaman) adalah lingkungan eksternal, hasil dari analisis SWOT dapat dijadikan basis untuk merumuskan strategi dan atau aksi.

Analisis SWOT adalah teknik yang sering digunakan sebagai bagian dari proses penyusunan perencanaan strategis. Untuk mencapai sasaran " Meningkatnya Daya Tampung Sekolah", maka strategi dan kebijakan yang ditempuh, adalah sebagai berikut :

Contoh : Analisis SWOT

\section{Identifikasi Faktor}

\begin{tabular}{|c|c|c|l|}
\hline NO & FAKTOR INTERNAL & & \\
\hline & Srengths & & Weaknesses \\
\hline S1 & Tersedianya Sekolah & W1 & Kualitas bangunan rendah \\
\hline S2 & & W2 & Terbatasnya anggaran \\
\hline S3 & FAKTOR EKSTERNAL & W3 & Ruang kelas terbatas \\
\hline & Opportunities & & Threaths \\
\hline 01 & Adanya dana alokasi khusus & T1 & Bencana alam \\
\hline 02 & Adanya partisipasi masyarakat & T2 & KKN \\
\hline 03 & Adanya sekolah swasta & T3 & Mahalnya harga tanah \\
\hline
\end{tabular}

Setelah disusun identifikasi faktor, selanjutnya dilakukan penilaian terhadap idntifikasi factor, yang memiliki nilai lebih dari factor lain disebut factor strategis yang merupakan kunci keberhasilan. Aspek yang dinilai dari tiap factor adalah : Urgensi factor terhadap misi, meliputi nilai Urgensi (NU) dan bobot factor (BF).

\section{Cara Menentukan Nilai-Nilai Urgensi dan Bobot Faktor.}

Untuk menentukan nilai urgensi (NU) dan bobot factor (BF) menggunakan matrik urgensi, penilaian dilakukan terhadap factor pendorong (strength dan opportunity) dan factor penghambat (weakness dan threats), seperti contoh dibawah ini : 
MATRIK URGENSI FAKTOR PENDORONG DAN PENGHAMBAT

\begin{tabular}{|c|l|c|c|c|c|c|c|c|c|}
\hline \multirow{2}{*}{ KODE } & \multicolumn{1}{|c|}{$\begin{array}{c}\text { FAKTOR } \\
\text { PENDORONG }\end{array}$} & \multicolumn{7}{|c|}{ MATRIK URGENSI } \\
\hline & & A & B & C & D & E & F & TOTAL & BOBOT(\%) \\
\hline A & Tersedianya Sekolah & X & A & A & D & A & A & 4 & 26.67 \\
\hline B & Tersedianya Guru & A & X & C & D & B & B & 2 & 13.33 \\
\hline C & Adanya kewenangan & A & C & X & D & D & D & 1 & 6.67 \\
\hline D & $\begin{array}{l}\text { Adanya Pinjaman } \\
\text { Perbankan }\end{array}$ & D & D & D & X & D & D & 5 & 33.33 \\
\hline E & $\begin{array}{l}\text { Adanya Partisipasi } \\
\text { Masyarakat }\end{array}$ & A & B & D & D & X & D & 2 & 13.33 \\
\hline F & $\begin{array}{l}\text { Adanya Sekolah } \\
\text { Swasta }\end{array}$ & A & B & D & D & E & X & 1 & 6.67 \\
\hline & \multicolumn{1}{|c|}{ JUMLAH } & & & & & & & 15 & 100 \\
\hline
\end{tabular}

Faktor kunci keberhasilan

\begin{tabular}{|l|l|c|c|c|c|c|c|c|c|}
\hline KODE & \multicolumn{1}{|c|}{$\begin{array}{c}\text { FAKTOR } \\
\text { PENGHAMBAT }\end{array}$} & \multicolumn{7}{|c|}{ MATRIK URGENSI } \\
\hline & & A & B & C & D & E & F & TOTAL & BOBOT (\%) \\
\hline A & $\begin{array}{l}\text { Kualitas bangunan } \\
\text { rendah }\end{array}$ & X & A & C & A & A & A & 4 & 26.67 \\
\hline B & Terbatasnya anggaran & A & X & C & B & B & B & 3 & 20 \\
\hline C & Ruang kelas terbatas & C & C & X & C & C & C & 5 & 33.33 \\
\hline D & Bencana Alam & A & B & C & X & E & F & - & 0 \\
\hline E & KKN & A & B & C & E & X & F & 1 & 6.67 \\
\hline F & Mahalnya harga tanah & A & B & C & F & F & X & 2 & 13.33 \\
\hline & JUMLAH & & & & & & & 15 & 100 \\
\hline
\end{tabular}

Dari matrik urgensi tersebut diatas bobot yang paling besar adalah : 
1. Untuk factor strength (kekuatan adalah tersedianya sekolah nilai $26,67 \%$

2. Untuk factor opportunity (peluang) adalah pinjaman Bank nilai 33,33\%

3. Untuk factor weaknesses (kelemahan) adalah ruang kelas terbatas nilai 33,33\%

4. Untuk factor threatment (ancaman) adalah mahalnya harga tanah nilai $13,33 \%$

Dengan demikian strategi yang akan ditetapkan untuk meningkatkan daya tampung sekolah, adalah sebagai berikut :

Formulasi Strategi SWOT

\begin{tabular}{|c|c|c|}
\hline $\begin{array}{c}\text { ANALISIS FAKTOR } \\
\text { INTERNAL } \\
\text { ANALISIS FAKTOR } \\
\text { EKSTERNAL }\end{array}$ & $\begin{array}{c}\text { DAFTAR KEKUATAN } \\
\text { INTERNAL } \\
\text { Tersedianya Sekolah }\end{array}$ & $\begin{array}{c}\text { DAFTAR } \\
\text { KELEMAHAN } \\
\text { INTERNAL } \\
\text { Ruang Kelas Terbatas }\end{array}$ \\
\hline $\begin{array}{c}\text { Daftar peluang } \\
\text { eksternal } \\
(0) \\
\text { Pinjaman Perbankan }\end{array}$ & $\begin{array}{c}\text { SO } \\
\text { Membangun Sekolah } \\
\text { Melalui Pinjaman Bank }\end{array}$ & $\begin{array}{c}\text { WO } \\
\text { Menambah ruang kelas } \\
\text { melalui pinjaman Bank }\end{array}$ \\
\hline $\begin{array}{c}\text { Daftar Ancaman } \\
\text { Eksternal } \\
\text { Mahalnya harga tanah }\end{array}$ & $\begin{array}{l}\text { ST } \\
\text { Atasi mahalnya harga } \\
\text { tanah untuk } \\
\text { membangun sekolah }\end{array}$ & $\begin{array}{c}\text { WT } \\
\text { Atasi ruang kelas yang } \\
\text { terbatas dengan } \\
\text { mengatasi mahalnya } \\
\text { harga tanah }\end{array}$ \\
\hline
\end{tabular}

Berdasarkan formulasi stratgei SWOT diatas, maka penentuan strategi dengan menggunakan teori tapisan, sebagaimana terlihat dalam table dibawah ini :

\begin{tabular}{|c|c|c|c|c|c|}
\hline NO & $\begin{array}{c}\text { ALTERNATIF } \\
\text { STRATEGI }\end{array}$ & EFEKTIVITAS & KEMUDAHAN & BIAYA & PRIORITAS \\
\hline 1 & $\begin{array}{c}\text { Membangun } \\
\text { sekolah } \\
\text { melalui } \\
\text { pinjaman } \\
\text { Bank }\end{array}$ & 5 & 4 & 3 & 12 \\
& $\begin{array}{c}\text { Menambah } \\
\text { ruang kelas }\end{array}$ & 5 & & & \\
\hline 2 & & 4 & 3 & 12 \\
\hline
\end{tabular}




\begin{tabular}{|c|c|c|c|c|c|}
\hline & $\begin{array}{c}\text { melalui } \\
\text { pinjaman } \\
\text { Bank }\end{array}$ & & & & \\
\hline 3 & $\begin{array}{c}\text { Atasi } \\
\text { mahalnya } \\
\text { harga tanah } \\
\text { untuk } \\
\text { membangun } \\
\text { sekolah }\end{array}$ & 4 & 3 & 3 & 10 \\
\hline 4 & $\begin{array}{c}\text { Atasi ruang } \\
\text { kelas yang } \\
\text { terbatas } \\
\text { dengan } \\
\text { mengatasi } \\
\text { mahalnya } \\
\text { harga tanah }\end{array}$ & 4 & 3 & 4 & 11 \\
\hline
\end{tabular}

Dengan demikian strategi untuk meningkatnya daya tampung sekolah adalah membangun sekolah dan menambah ruang kelas melalui pembiayaan dana pinjaman Bank. Selanjutnya kebijakan, program, dan kegiatan yang akan dilakukan adalah sebagai berikut :

Strategi, Kebijakan, Program, dan Kegiatan

\begin{tabular}{|l|l|l|l|l|}
\hline SASARAN & STRATEGI & $\begin{array}{l}\text { KEBIJAKA } \\
\mathrm{N}\end{array}$ & PROGRAM & KEGIATAN \\
\hline $\begin{array}{l}\text { Meningkatn } \\
\text { ya daya } \\
\text { tampung } \\
\text { sekolah }\end{array}$ & $\begin{array}{l}\text { Membang } \\
\text { un sekolah } \\
\text { dan } \\
\text { menambah } \\
\text { ruang } \\
\text { kelas }\end{array}$ & $\begin{array}{l}\text { Perluasan } \\
\text { gedung } \\
\text { sekolah } \\
\text { bertingkat }\end{array}$ & $\begin{array}{l}\text { Pembangun } \\
\text { an gedung } \\
\text { sekolah } \\
\text { bertingkat }\end{array}$ & $\begin{array}{l}\text { 1. Membangun } \\
\text { gedung } \\
\text { sekolah } \\
\text { bertingkat } \\
\text { 2. Menyediakan } \\
\text { sarana } \\
\text { prasarana } \\
\text { pendidikan }\end{array}$ \\
\hline
\end{tabular}

Demikianlah salah satu contoh cara menyusun arah dan kebijakan umum APBD, sudah barang tentu sasaran yang ingin dicapai oleh pemerintah daerah itu banyak, maka setiap sasaran yang ingin dicapai dibuat arah dan kebijakan umumnya, manfaatnya dibuat arah dan kebijakan ini, tiada lain agar penggunaan anggaran dapat berjalan secara berdata guna dan berhasil guna. Pada gilirannya kinerja Pemda menjadi produktif. 


\section{Kesimpulan}

Dalam pelaksanaan otonomi daerah secara luas, nyata, dan bertanggung jawab, diperlukan adanya reformasi anggaran. Aspek utama dari reformasi anggaran adalah perubahan anggaran dari tradisional budget kepada performance budget. Salah satu komponen yang harus dikembangkan sebagai dasar pengukuran kinerja adalah menyusun Standar Analisa Belanj (SAB). SAB merupakan standard atau pedoman yang bermanfaat untuk menilai kewajaran atas beban kerja dan biaya terhadap suatu kegiatan yang direncanakan. SAB digunakan untuk menilai dan menentukan rencana program, kegiatan dan anggaran belanja yang paling efektif dalam upaya pencapaian kinerja. Dengan APBD disusun berdasarkan pendekatan kinerja maka dalam APBD harus jelas sasaran yang akan dicapai dalam satu tahun anggaran. Sasaran termaksud ditetapkan dalam arah dan kebijakan umum APBD yang ditetapkan oleh Pemerintah Daerah bersama DPRD. Arah dan Kebijakan Umum merupakan petunjuk dan ketentuan-ketentuan umum yang disepakati sebagia pedoman dalam penyusunan APBD. Arah dan kebijakan umum APBD disamping merupakan instrument perencanaan anggaran juga sebagai dasar untuk penilaian kinerja keuangan daerah. Dalam penyusunan arah dan kebijakan umum APBD,Pemerintah Daerah harus tetap mempertimbangkan dokumen-dokumen pemerintah lainnya seperti : rencana strategis daerah, hasil evaluasi kerja pemerintah periode sebelumnya, pokok pikiran DPRD dan Arahan dari Pemerintah Pusat. Teknik penyusunan arah dan kebijakan umum menggunakan pohon masalah, pohon sasaran, pohon alternative, teknik USG dan analisis SWOT. 


\section{Daftar Pustaka}

Kuncoro, Mudrajad. 2002. Otonomi Dan Pembangunan Daerah. Jakarta : Eelangga.

Mardiasmo. 2002. Otonomi Dan Manajemen Keuangan Daerah. Yogyakarta : Penerbit Andi.

Martini Huseini dan Moenek Reydonnizar. 2004. Manajemen Keuangan Daerah Dan Anggaran Kinerja. Jakarta : Departemen Dalam Negeri.

Ndraha, Talizuduhu. 1985. Research, Teori Metodologi Administrasi. Jakarta : Bina Aksara.

Subandi, Aban. 2003. Administrasi Keuangan Negara. Bandung : Rizki Press.

Sanipar, J.P.G. dan Entang, H.M. 2003. Teknik-Teknik Analisis Manajemen. Jakarta : Lembaga Administrasi Negara.

Timpe A. Dale. 1992. Kinerja (Performance). Jakarta : Gramedia Asri Media 